University of Nebraska - Lincoln

DigitalCommons@University of Nebraska - Lincoln

2012

Transparent Armor Ceramics as Spacecraft Windows

Jonathan Salem

NASA Glenn Research Center, jonathan.a.salem@nasa.gov

Follow this and additional works at: https://digitalcommons.unl.edu/nasapub

Salem, Jonathan, "Transparent Armor Ceramics as Spacecraft Windows" (2012). NASA Publications. 121. https://digitalcommons.unl.edu/nasapub/121

This Article is brought to you for free and open access by the National Aeronautics and Space Administration at DigitalCommons@University of Nebraska - Lincoln. It has been accepted for inclusion in NASA Publications by an authorized administrator of DigitalCommons@University of Nebraska - Lincoln. 


\title{
Transparent Armor Ceramics as Spacecraft Windows
}

\author{
Jonathan A. Salem*,† \\ NASA Glenn Research Center, Cleveland, OH 44135
}

\begin{abstract}
The slow crack growth parameters of several transparent armor ceramics were measured as part of a program to lighten next generation spacecraft windows. Transparent magnesium aluminate (spinel, $\mathrm{MgAl}_{2} \mathrm{O}_{4}$ ) and $\mathrm{AION}$ exhibit superior slow crack resistance relative to fused silica, which is the historical material of choice. For spinel, slow crack growth, strength, and fracture toughness are significantly influenced by the grain size, and alumina-rich phases and porosity at the grain boundaries lead to intergranular fracture in coarse grain spinel. Functions describing the required mass for a desired window life imply that transparent ceramics can lighten window panes from a slow crack growth perspective.
\end{abstract}

\section{Introduction}

$\mathrm{W}$ INDOw materials in spacecraft such as the Space Shuttle must meet many requirements such as maintaining cabin pressure for the design life of the vehicle; sustaining rapid high heating followed by rapid cooling (thermal shock); tolerating damage from impacts at low, high, and hyper- velocities; providing superior optical characteristics for piloting, imagery, and science; and tolerating a variety of earth and space environmental constituents.

As a result, implementation of a new material requires substantial investigation. Only one material has been researched and used extensively: fused silica. Fused silica has performed well in the space shuttle orbiter and the international space station (ISS) with no catastrophic failures. However, fused silica widows have been taken out of service due to various forms of damage. Thus, the use of new materials with superior characteristics could improve window lifetime and possibly lighten the window systems.

Transparent armors and other recently developed materials exhibit superior ballistic performance as compared to glass ${ }^{1}$ and thus are being investigated by NASA. Under consideration at NASA are spinels, AlON, and various plastics via the efforts of multiple centers. Optical, thermal, and mechanical properties are being measured. The ultimate goal of the program is to generate a database that can be used by designers to develop windows for a variety of applications.

This article provides slow crack growth parameters and fracture toughness of transparent ceramics; knowing these properties is essential for the lifetime design of pressurized windows. Although relatively mature test methods were applied, some modifications of the test methods were developed. These modifications resulted in improved parameter estimates and in some cases have been balloted into ASTM (American Society for Testing and Materials) test methods.

V. Sglavo-contributing editor

Manuscript No. 31645. Received July 3, 2012; approved October 16, 2012. Presented in part at 35th International Conference \& Exposition on Advanced Ceramics and Composites, January 24, 2011.

* Member, American Ceramic Society.

† Author to whom correspondence should be addressed. email: Jonathan.a. salem@nasa.gov
In addition to generating material properties, an equation is derived to estimate the required window pane mass in terms of crack growth parameters and specified lifetime.

\section{Test Materials}

To date, transparent spinel $\left(\mathrm{MgAl}_{2} \mathrm{O}_{4}\right)$ and aluminum-oxynitride $(\mathrm{AlON})$ have been tested by using specimens extracted from both the surface and the center of several billets representative of the size of spacecraft windows. As a point of reference, the same methods were used to test fused silica extracted from a retired window of Shuttle Orbiter OV-103. Work continues on the testing of spinels, AlON, and a Russian-made fused silica being used in the ISS. The commercially manufactured spinels exhibited different grain sizes and are designated TA, AL, and CT, respectively. Data on two other spinels are reported: The spinel tested at NASA LaRC in the $1980 \mathrm{~s}^{2}$ and that recently tested at Forschungszentrum Jülich. The absorption coefficients of the test materials ranged from 0.4 to $1.6 \mathrm{~cm}^{-1}$ at $5 \mu \mathrm{m}$.

\section{Experimental Procedure}

American Society for Testing and Materials Committee C28 has developed a variety of test standards for measuring the properties of monolithic and composite ceramics such as silicon nitride and silicon carbide. ${ }^{3}$ These methods were generally successful for transparent ceramics and fused silica. However, as with new or different material systems, some modification in the test methods, as described in the following sections, were necessary.

\section{(1) Elastic Constants and Grain Size}

Elastic constants were measured by using ASTM C1298 with $32 \mathrm{~mm}$ diameter circular disks, ${ }^{4,5}$ which allow rapid estimation of Poisson's ratio and Young's modulus from a specimen that can also be used to determine strength and slow crack growth parameters. Grain size was determined via ASTM E112.

\section{(2) Fracture Toughness}

Fracture toughness was performed with ASTM C1421, 7,8 however, due to the coarse grain structure exhibited by the spinels, the crack length in single-edged precracked beam (SEPB) specimens could not be optically measured. Thus, the crack lengths were estimated via the compliance as measured with backface strain. ${ }^{9}$ Testing of fused silica was complicated by formation of steps rather than a smooth plane, and a slightly elevated fracture toughness resulted $\left(K_{\mathrm{Ipb}}=0.77\right.$ vs $0.73 \mathrm{MPa} \sqrt{\mathrm{m}}$ in dry nitrogen). The elevated fracture toughness resulted from pinning of the cracks at the steps, as denoted by the arrows in Fig. 1. The cracks were also noted to close so completely that they are difficult to be visually detected.

The chevron notch (VB) was also used to test some of the materials. One inference encountered in fracture toughness testing with the VB was unstable crack extension, especially 


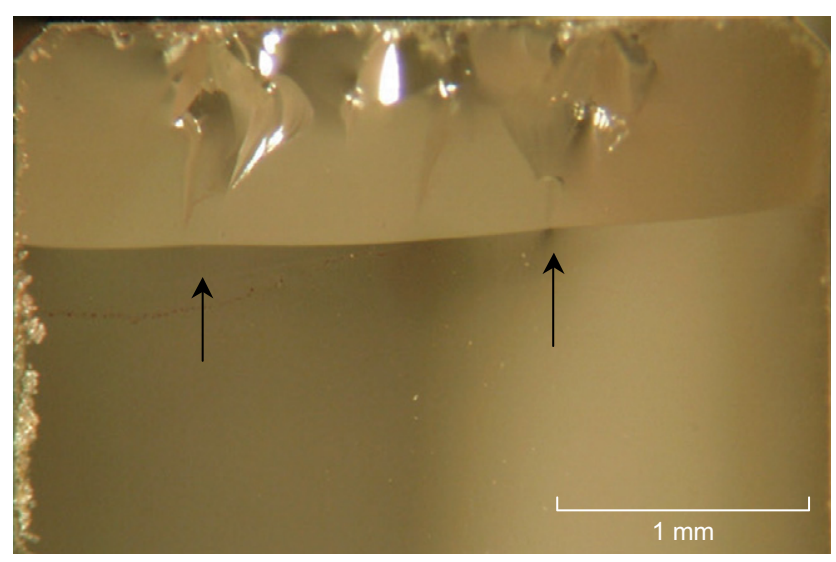

Fig. 1. Fracture surface of a fused silica SEPB specimen. Arrows indicate bowing of the crack front in line with indentations used to start a precrack.

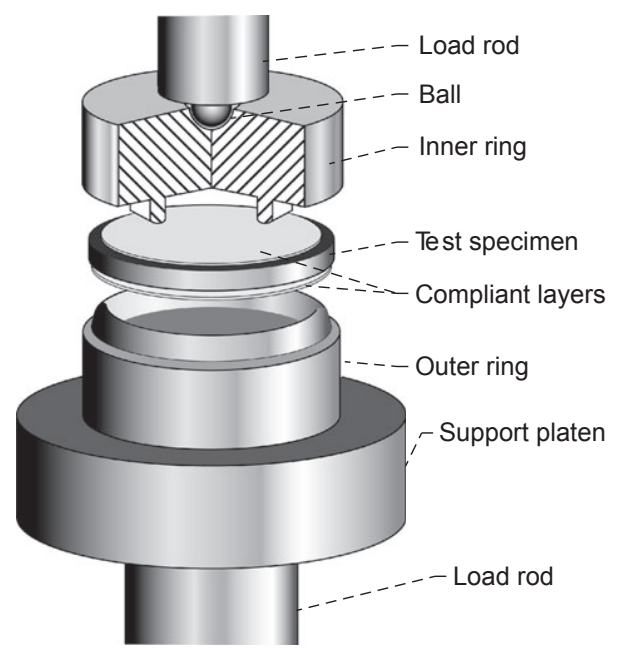

Fig. 2. Test configuration for biaxial strength and slow crack growth.

in dry nitrogen. This is the result of improved machining of the notches, which results in less machining damage at the notch root where the crack initiates. Stability was assured by precracking specimens in humid air, as monitored by a strain gauge on the back-face. The specimens were then tested as usual in nitrogen. More aggressive machining of the notches was also found to promote stability.

\section{(3) Uniaxial Strength}

Uniaxial strength of spinel (TA) was determined by machining ASTM C1161 B flexure specimens ${ }^{10}$ from the as-supplied, polished billet surfaces. Both the polished and ground (interior) surfaces were tested in tension in water and dry nitrogen to determine the effects of position, finish, and environment. Testing in dry nitrogen was conducted at $60 \mathrm{MPa} / \mathrm{s}$ while testing in water was conducted at $6 \mathrm{MPa} / \mathrm{s}$ for comparison to biaxial strength tests conducted at the same stress rates.

\section{(4) Slow Crack Growth}

For measurement of the slow crack growth parameters $A$ and $n$, the nominal procedures of ASTM C1368 ${ }^{11}$ were applied. However, as optical materials tend to have low fracture toughness $(<2 \mathrm{MPa} \sqrt{\mathrm{m}})$ and thus are sensitive to edge finish, disks were used instead of beams. Disks are more akin to window applications and provide more effective sampling

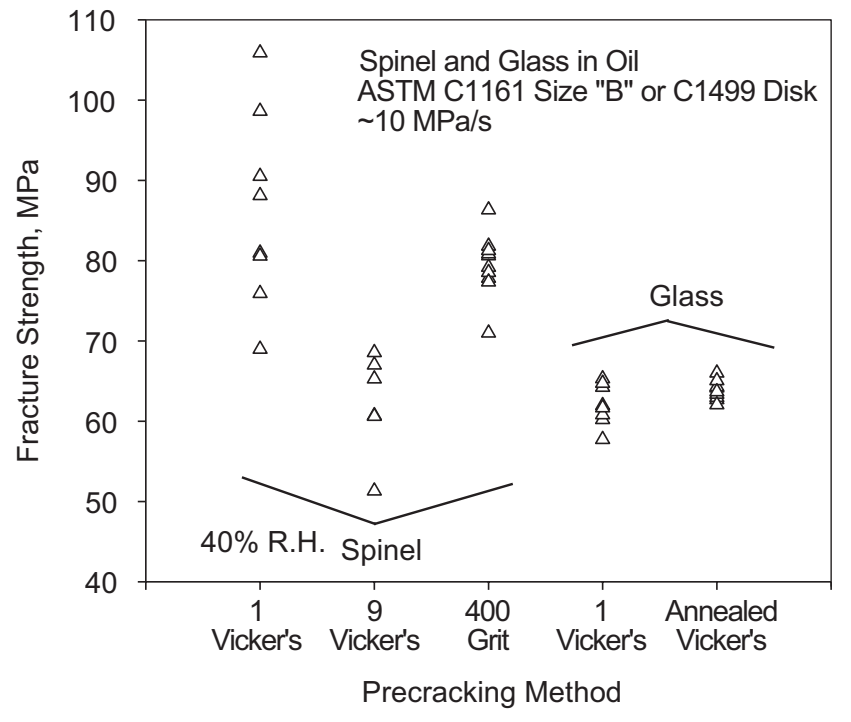

Fig. 3. Fracture strength of ground and indented spinel.
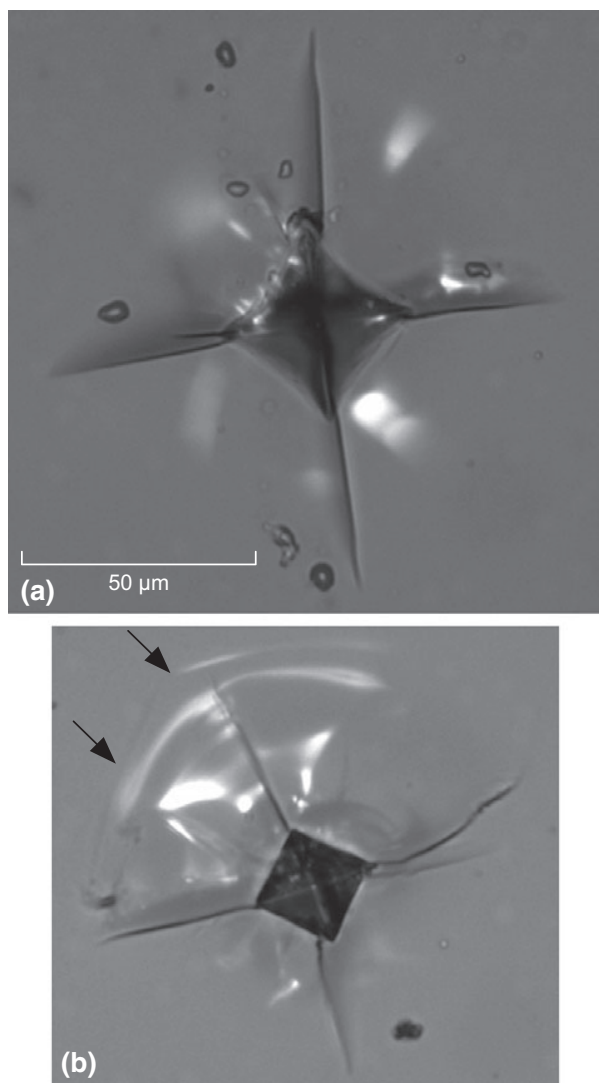

Fig. 4. Indents formed with $0.5 \mathrm{~kg}$ in (a) soda-lime glass and (b) spinel. Arrows denote a lateral crack.

of the intrinsic material flaws and any surface damage as compared to uniaxial beams because of the biaxial stress state. The nominal test configuration is shown in Fig. 2. ${ }^{12,13}$ The $32 \mathrm{~mm}$ diameter, $1.75 \mathrm{~mm}$ thick disks were loaded with 25 and $12.5 \mathrm{~mm}$ rings at stress rates between 0.0001 and $10 \mathrm{MPa} / \mathrm{s}$. Higher stress rates were generally avoided to ensure development of a defined crack prior to failure and domination by region I of the slow crack growth curve. ${ }^{14}$

Because scatter can make it difficult to estimate crack growth parameters, an attempt was made to use indentation to form consistent cracks on test specimens. Unfortunately, indentation of the spinels and fused silica produced less 
Table I. Grain size, Elastic Constants, and Fracture Toughness of Transparent Ceramics

\begin{tabular}{|c|c|c|c|c|c|c|}
\hline \multirow[b]{2}{*}{ Material } & \multirow{2}{*}{$\begin{array}{l}\text { Nominal Grain Size }(\mu \mathrm{m}) \\
\text { Mean/Median }\end{array}$} & \multirow[b]{2}{*}{ Bulk Density $\left(\mathrm{g} / \mathrm{cm}^{3}\right)$} & \multirow[b]{2}{*}{ Young's Modulus (GPa) } & \multirow[b]{2}{*}{ Poisson's Ratio } & \multicolumn{2}{|c|}{$\begin{array}{l}\text { Average Fracture Toughness } \\
\qquad(\mathrm{MPa} \sqrt{\mathrm{m}})\end{array}$} \\
\hline & & & & & $65 \%$ RH Air & Dry $\mathrm{N}_{2}$ \\
\hline Spinel (AL) & $180 / 150$ & 3.555 & $267 \pm 2$ & 0.27 & $1.48 \pm 0.11$ & $1.60 \pm 0.17$ \\
\hline Spinel (CT) & 110 & 3.561 & $269 \pm 0.4$ & 0.27 & $1.66 \pm 0.11$ & $1.72 \pm 0.25$ \\
\hline Spinel (LaRC) & 25 & - & - & - & $1.90\left(\mathrm{H}_{2} \mathrm{O}\right)$ & $2.38^{\dagger}$ \\
\hline Fused Silica & - & 2.196 & $72 \pm 0.2$ & 0.18 & $0.72 \pm 0.05$ & $0.76 \pm 0.03$ \\
\hline
\end{tabular}

${ }^{\dagger}$ Notched beam, reference [2].

${ }^{ \pm}$Indentation fracture, references [20,21].

The values following \pm are one standard deviation.

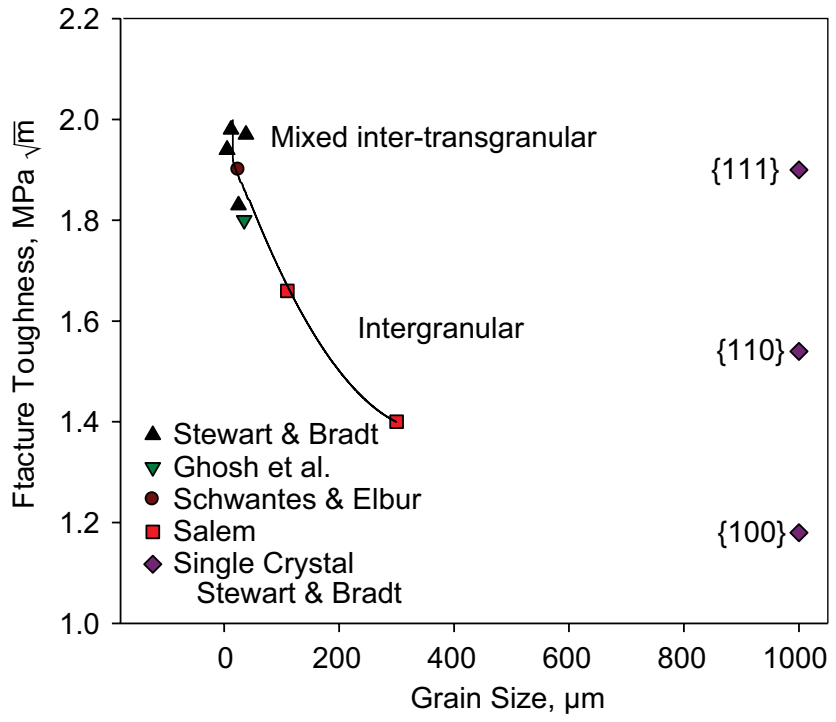

Fig. 5. Fracture toughness as a function of grain size for spinel.
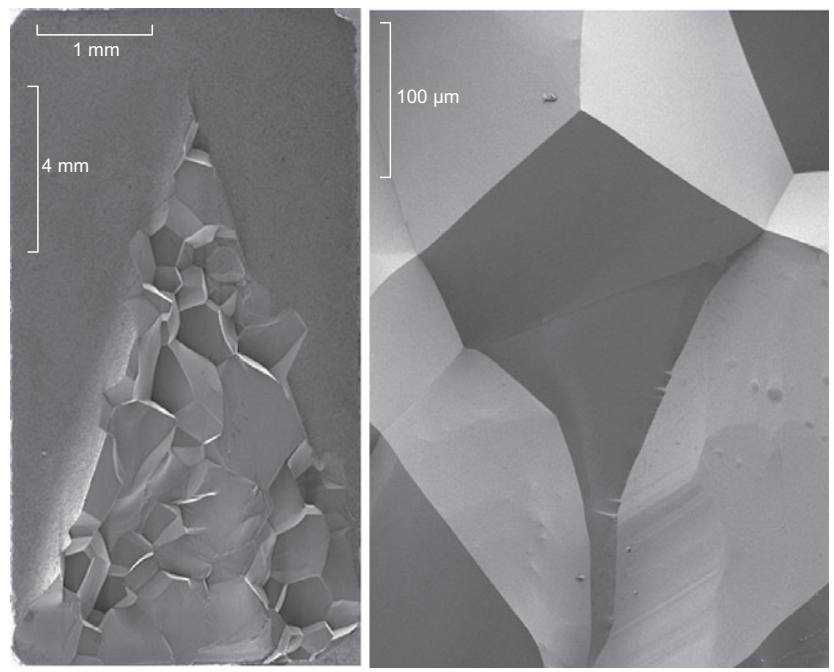

Fig. 6. Scanning electron fractograph of a spinel (TA) chevronnotch specimen.

consistent cracks and fracture strengths than simple 400 grit diamond grinding.

The lower scatter associated with grinding can be explained by sampling of a distribution of flaws existing on a material. Diamond grinding of an optical material produces
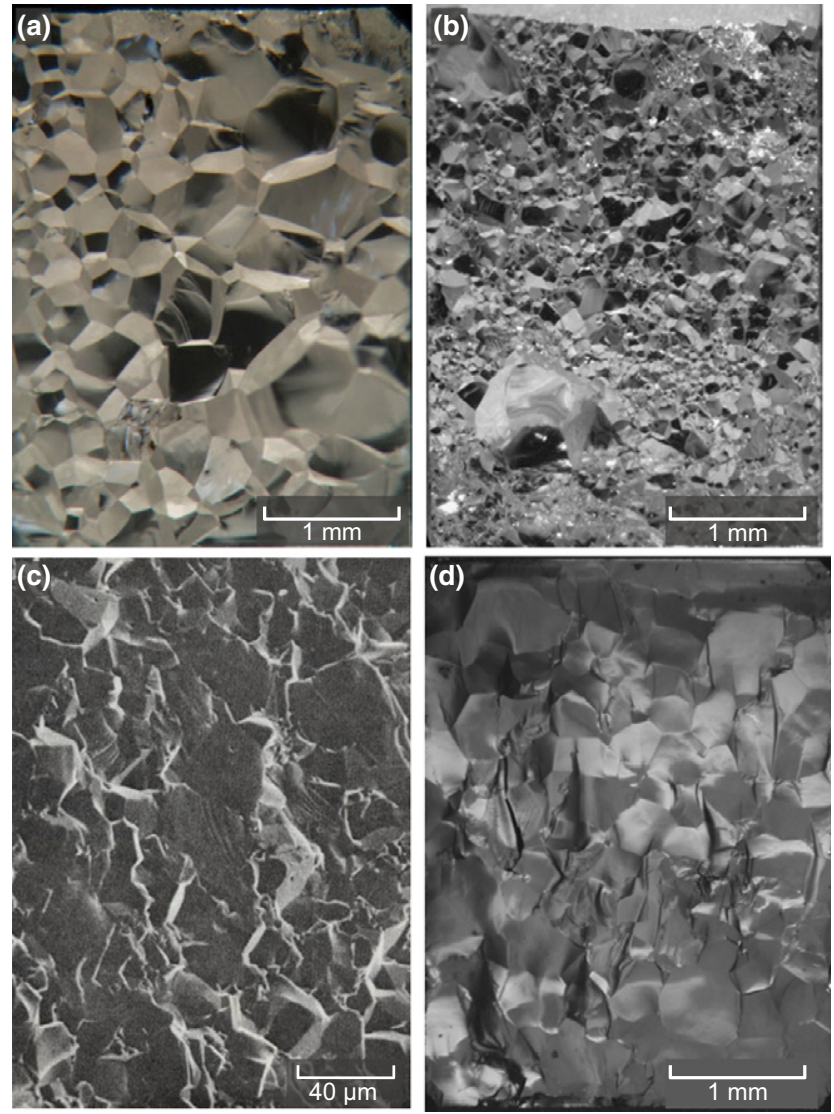

Fig. 7. Fracture surfaces of transparent ceramic, SEPB specimens: (a) spinel (TA), (b) spinel (CT), (c) spinel (LaRC), and (d) AlON.

a multiplicity of cracks that are sampled with a single strength test because the worst flaw present from the distribution controls failure. Indentation produces a single crack on each specimen, making each test a single sample from a distribution. The measured scatter of single flaw tests is increased because the whole distribution is sampled rather than the extreme values. The measured scatter associated with a multiplicity of flaws is reduced because an extreme value is immediately sampled.

Increasing the number of indentations on a specimen can mitigate scatter. The effect of increasing the number of indentation flaws in a sample from one to nine as compared to the many flaws produced by grinding can be seen in Fig. 3. For spinel, the coefficient of variation $(\mathrm{CV})$ is reduced from $15 \%$ to $10 \%$ for nine indentations. Grinding reduces the $\mathrm{CV}$ to $7 \%$. Ideally the $\mathrm{CV}$ of strength should be $<10 \%$ so that propagation of errors can be used to estimate 
Table II. Fracture Toughness with Standard Deviation by the SEPB and VB Techniques

\begin{tabular}{|c|c|c|c|c|}
\hline \multirow[b]{2}{*}{ Material } & \multicolumn{4}{|c|}{ Fracture Toughness $\mathrm{MPa} \sqrt{\mathrm{m}}$} \\
\hline & Lab Air $(45 \%-65 \%$ RH $)$ & Dry $\mathrm{N}_{2}$ & Lab Air $(45 \%-65 \% \mathrm{RH})$ & Dry $\mathrm{N}_{2}$ \\
\hline Spinel (TA) & $1.32 \pm 0.05$ & $1.52 \pm 0.07$ & $1.48 \pm 0.14$ & $1.58 \pm 0.08$ \\
\hline Spinel (AL) & & & $1.48 \pm 0.11$ & $1.60 \pm 0.17$ \\
\hline Spinel (CT) & $1.66 \pm 0.11$ & $1.72 \pm 0.25$ & - & - \\
\hline
\end{tabular}

Values following \pm are one standard deviation.

Table III. Biaxial Strength Statistics for Silicone Oil

\begin{tabular}{lcc}
\hline Material & Mean Strength, $S_{f}(\mathrm{MPa})$ & Weibull Modulus, $m$ \\
\hline Spinel (TA) & $80 \pm 4(10)$ & $24 \pm 8$ \\
Spinel (AL) & $60 \pm 5(20)$ & $14 \pm 3$ \\
Spinel (CT) & $68 \pm 7(10)$ & $12 \pm 4$ \\
Spinel (LaRC) & 166 & - \\
Spinel (Julich) ${ }^{\dagger}$ & $155 \pm 25$ & $6 \pm 2$ \\
AlON & $206 \pm 9(10)$ & $23 \pm 7$ \\
Fused Silica & $79 \pm 9(12)$ & $11 \pm 3$ \\
\hline
\end{tabular}

${ }^{\dagger}$ Laboratory air, reference [20,21]

Values following \pm are one standard deviation; the number of test specimens are given in brackets.

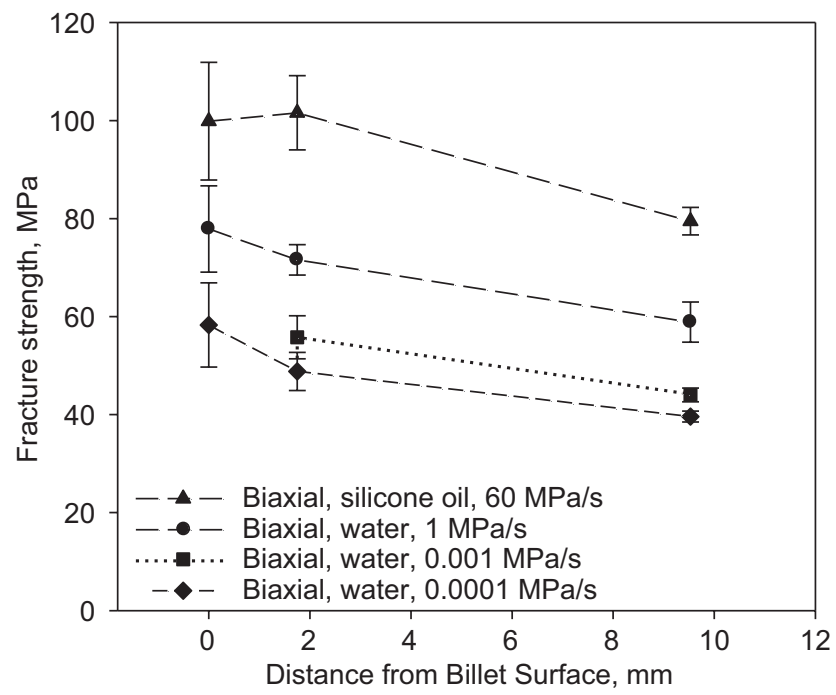

Fig. 8. Biaxial strength as a function of position through the billet thickness for spinel (TA).

variances associated with parameters. For glass, a 3\% coefficient of variation is attained immediately due to very repeatable indentation cracking, with indentation precracks giving similar crack growth parameters to smaller grinding flaws, ${ }^{15}$ but with much less scatter. Spinel does not produce repeatable indentation cracks: incomplete lateral cracks that compete with the median cracks are formed, as shown in Fig. 4, and strength variation increases.

Although the coarse grain size of some of the materials studied can interfere when using common test specimens, the use of surface grinding and disks specimens ensures that many grains and cleavage planes are given the opportunity to induce failure. Interestingly, the chevron-notch fracture toughness specimens, which only tested a few grains in the coarse spinels, did not exhibit unusual scatter, implying little complication of microstructural scale relative to test specimen dimensions.

\section{Results}

(1) Elastic Constants and Grain Size

The elastic constants are summarized in Table I. Some dependence of modulus and density was exhibited for spinel (TA). AlON exhibited a very narrow range of density and modulus.

All test materials exhibited a very wide grain size distribution $(\sim 10 \mu \mathrm{m}$ to $\sim 1 \mathrm{~mm})$, with the spinel (TA) occasionally exhibiting grains larger than $1 \mathrm{~mm}$. Spinel (CT) was generally finer with grains between 20 and $400 \mu \mathrm{m}$, and rarely exhibited grains larger than $1 \mathrm{~mm}$.

\section{(2) Fracture Toughness}

Table I demonstrates that fracture toughness is consistently lower in water or high humidity air as compared to dry nitrogen, implying stress corrosion susceptibility. Fracture toughness as a function of grain size for spinels is shown in Fig. 5, and supports the conclusion of Stewart and Bradt ${ }^{16,17}$ of little practical effect of grain size at fine sizes. However, for very coarse gain structures a trend emerges along with a transition to intergranular failure, Fig. 6. This transition was suspected to result from the collection of submicrometer pores that were observed at some grain boundaries. ${ }^{18}$ However, electron microscopy of fracture surfaces revealed porosity, tabular alumina, and alumina-rich regions in spinels (TA) and (CT), as discussed in the fractography section. It is noteworthy that the fracture toughness of coarse-grained spinel approaches that of the (100) plane, ${ }^{19}$ implying that cleavage of coarse grains may also contribute to the low fracture toughness.

One minor exception to the grain size-fracture toughness trend is the data reported at a recent conference (Refs. ${ }^{20,21}$ ). Considering the fine grain size $(5 \mu \mathrm{m})$ one would expect fracture toughness of $\sim 2 \mathrm{MPa} \sqrt{\mathrm{m}}$. However, 1.6-1.8 MPa $\sqrt{\mathrm{m}}$ was measured by using indentation techniques. Indentation assumes a well-defined median crack. However, both coarse (Fig. 4) and $25 \mu \mathrm{m}^{2}$ spinels produce poor indentation cracks, making indentation techniques unsuitable for coarser spinels and possibly inaccurate for fine spinels. Steinbrech et $\mathrm{al}^{20} \mathrm{did}$ show a well-formed indentation, so the difference is unexplained. A variety of other brittle materials, such as $\mathrm{ZnSe}$ and fused silica, exhibit poor indentation crack formation and render indentation techniques inapplicable.

Aluminum oxynitride exhibits the greatest fracture toughness and the least effect of water vapor. The fracture surface of AlON and several spinels is shown in Fig. 7, and result from both the SEPB and VB test methods are compared in Table II. For engineering purposes, the methods give equivalent values.

\section{(3) Strength and Slow Crack Growth}

The initial strength of very brittle optical materials depends on the surface damage imparted during machining and handling, and any inherent processing flaws. The strength can vary further because of subcritical crack growth, which decreases strength with time under load. The inherent property 
Table IV. Mean Uniaxial and Biaxial Strength of Spinel (TA) as a Function of Depth from Billet Surface

\begin{tabular}{lcccc}
\hline 10 per condition & \multicolumn{2}{c}{ Uniaxial Strength $(\mathrm{MPa})$} & \multicolumn{2}{c}{ Biaxial Strength (ground) $(\mathrm{MPa})$} \\
\hline Test surface depth, mm & 0 (polished) & 3 (ground) & 0 & 1.75 \\
Inert & $107 \pm 12$ & $108 \pm 15$ & $100 \pm 17$ & $102 \pm 11$ \\
Water $(6 \mathrm{MPa} / \mathrm{s})$ & $72.9 \pm 11$ & $80.3 \pm 8.0$ & $78.1 \pm 12$ & $71.6 \pm 4.4$ \\
\hline
\end{tabular}

Values following \pm are one standard deviation.

is fracture toughness. However, as strength is still a popular and necessary metric, the measured, inert biaxial strengths and associated statistical parameters are listed in Table III. The data are representative of an ASTM C1161 400 grit diamond grind as provided by commercial machining houses; however, the materials were not all ground at the same time or by the same commercial vendor, and spinel (CT) exhibited a rougher finish than the other materials. Finer spinels generally exhibit greater strength than coarse spinels. AlON, which has the greatest fracture toughness, exhibits the greatest strength. In most cases, only 10 specimens were tested, making Weibull parameter estimates highly variable.

For spinel (TA), strength was determined as a function of location through the billet thickness. As shown in Fig 8, the strength and variance are greatest at the surface regardless of environment and stress rate, making Weibull scaling difficult. Uniaxial flexure of spinel (TA) specimens with ground or polished finishes gave the same results as ground biaxial strength specimens, confirming the intergranular nature of failure and implying a weak scale effect, Table IV.

Table V summarizes slow crack growth parameters based on

$$
v=A K_{\mathrm{I}}^{n}
$$

where $v$ is crack velocity, $K_{\mathrm{I}}$ is the applied stress intensity, and $A$ and $n$ are materials constants. The results imply that grain refinement improves quasi-static properties of spinel. Coarse grain spinels exhibit an exponent $n$ similar to glass whereas fine grain spinel is as resistant as alumina. Fig. 9 compares crack velocities of spinels and AlON to that of fused silica. The transparent ceramics exhibit substantially better crack growth properties than fused silica. AlON is not as resistant to slow crack growth as might be expected from the fracture toughness results.

Figure 10 shows the effect of stress rate on the fracture pattern of soda-lime glass and spinel. At all stress rates, spinel exhibits a very rough fracture pattern as compared to glass, and fine debris separated from the specimens as shown in Fig. 11. The debris is grains and parts of grains that separate from the bulk material upon fast fracture, implying a weak grain-boundary structure.

The effect of rapid stress rates on strength can be seen in Fig. 12 for two independently generated data sets. The curves clearly show plateaus at the highest rates. The corresponding crack growth exponents shift from $\sim 28$ to $\sim 23$ (fused silica) and $\sim 26$ to $\sim 22$ (low expansion glass ${ }^{22}$ ) when highest rates are included in the regression fits. The presence of a plateau in these materials is either a coincidence, or a finite "incubation" time is required for a sharp crack to develop and grow significantly. The transparent ceramics were tested at lower rates to avoid any plateau.

An attempt was also made to grow macro-cracks in spinel (AL) by cyclic fatigue loading of compact tension specimens. A crack could be formed only in the central region of the specimen as shown in Fig. 13, implying heterogeneity between the billet surface and center in agreement with the results of Fig. 8. The increasing strength and crack growth resistance from billet center to surface corresponds to a change in grain size from $150-275 \mu \mathrm{m}$ to $250-450 \mu \mathrm{m}$. This may explain the unexpected large strengths observed when
Table V. Slow Crack Growth Parameter $n$ with Standard Deviation and Window Mass Relative to that for Fused Silica

\begin{tabular}{lcccc}
\hline \multicolumn{5}{c}{$v=A K_{\mathrm{I}}{ }^{n}$} \\
Material & $\begin{array}{c}\text { Grain Size, } \\
(\mu \mathrm{m})\end{array}$ & $n$ (all data) & $n$ (medians) & $\begin{array}{c}\text { Relative } \\
\text { Mass }\end{array}$ \\
\hline Spinel (TA) & 280 & $22 \pm 2$ & $21 \pm 1$ & 1.14 \\
Spinel (AL) & 180 & $25 \pm 2$ & $25 \pm 2$ & 1.04 \\
Spinel (CT) & 110 & $32 \pm 3$ & $28 \pm 3$ & 0.97 \\
Spinel (LaRC) ${ }^{2}$ & 25 & $39 \pm 4$ & $35 \pm 3$ & 0.74 \\
Spinel (Julich) ${ }^{1,21}$ & 5 & 50 & - & 0.73 \\
AlON $_{\text {Fused Silica }}$ & 245 & $33 \pm 5$ & $36 \pm 5$ & 0.83 \\
& - & $23 \pm 2$ & $23 \pm 2$ & 1 \\
\hline
\end{tabular}

Values following \pm are one standard deviation.

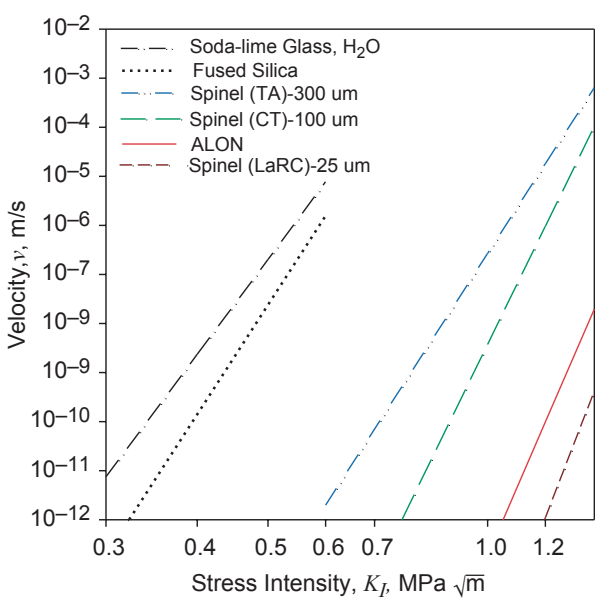

Fig. 9. Crack velocity as a function of stress intensity in water.

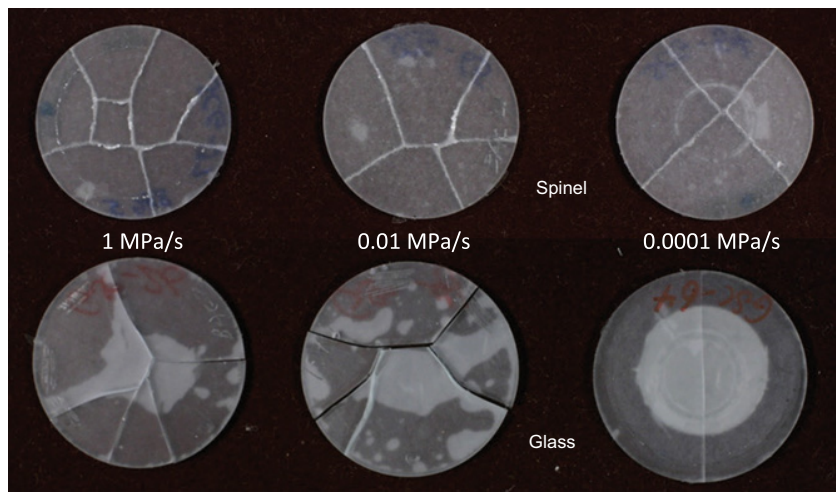

Fig. 10. Fracture patterns in spinel (TA) and soda-lime glass as a function of stress rate. Spinel exhibits a rough fracture pattern relative to glass.

small surface specimens are tested ${ }^{18}$ : small specimens only sample the very coarse surface region that resists fracture.

It is noteworthy that the skin effect exhibited by the coarse spinel (TA) is counter to the overall trend of increasing strength with decreasing grain size. This is believed to be due 


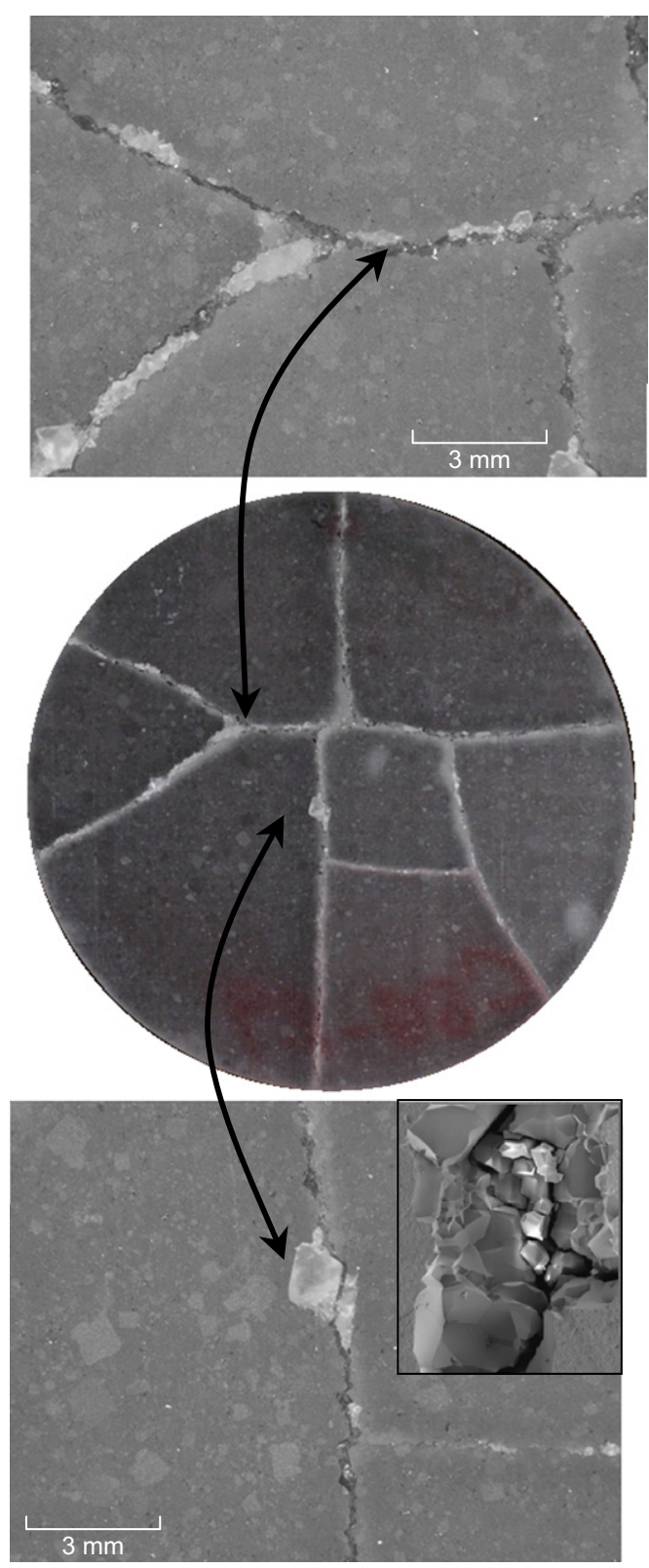

Fig. 11. Localized bifurcation in spinel (CT) leading to pop-out of large grains and formation of debris. Inset gives detail of debris.

to better stoichiometry near the billet surface; however, efforts to quantitatively demonstrate this were inconclusive.

\section{(4) Sources of Failure}

Fractography of the spinels was complicated by low failure stress, large mirror size relative to specimen thickness, coarse grain structure, and loss of material along the crack path, including that containing the origin. However, two sources of failure were readily observed in spinel (TA): very large grains and alumina particles at grain boundaries. Fig. 14 shows a large grain in a uniaxial strength specimen and Fig. 15 shows alumina particles and alumina rich regions along grain-boundary fracture paths. The boundary composition is quite variable with some regions dense in fine, semicircular particles and others sparsely populated with large, angular particles, Fig. 16.

\section{(5) Residual Stress and Texture}

The presence of tabular alumina crystals at the spinel grain boundaries produces localized residual stresses and explains

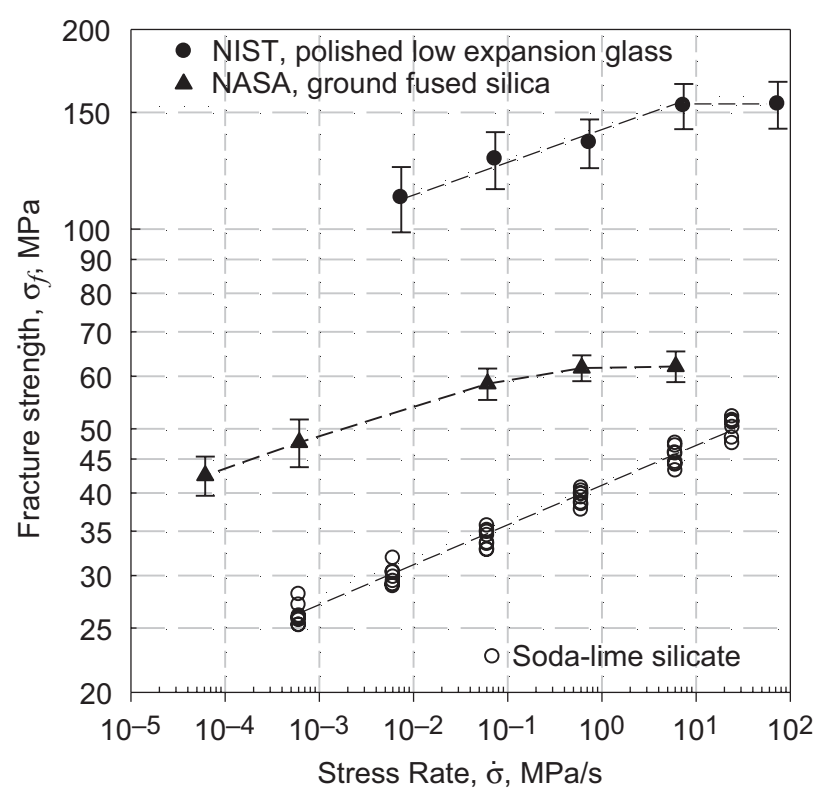

Fig. 12. Strength in distilled water with $95 \%$ confidence intervals as a function of stress rate. Fused silica and low expansion glass exhibit plateaus at higher loading rates.

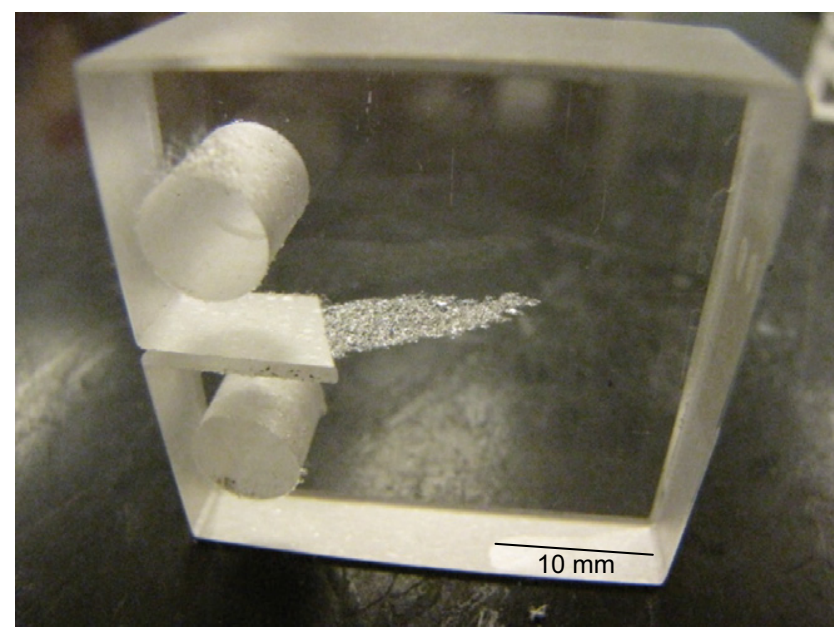

Fig. 13. Spinel (AL) compact tension specimen showing crack tunneling from the starter notch.

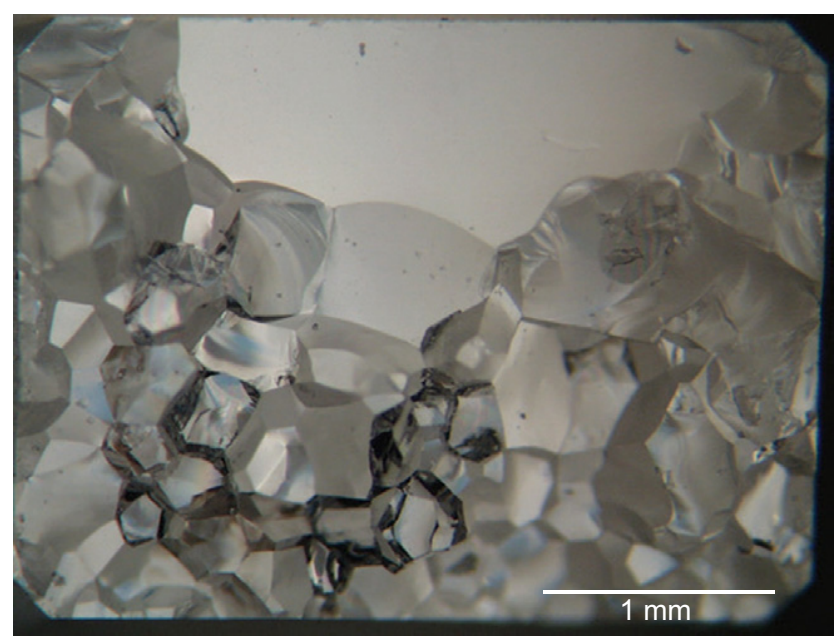

Fig. 14. Grain failure in spinel (TA). 

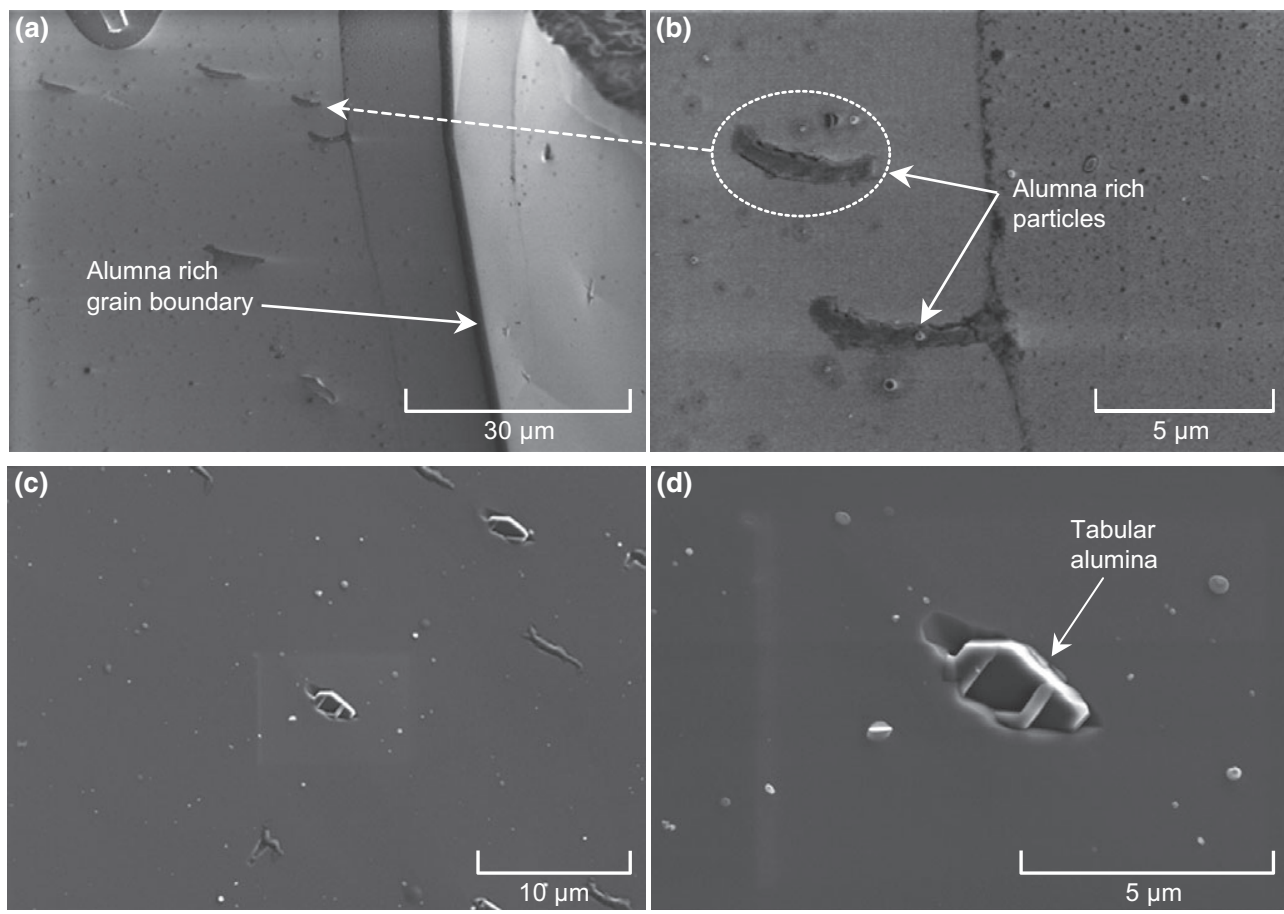

Fig. 15. Grain boundaries in spinel (TA): (a) and (b) alumina-rich boundary and particles; (c) and (d) tabular alumina.
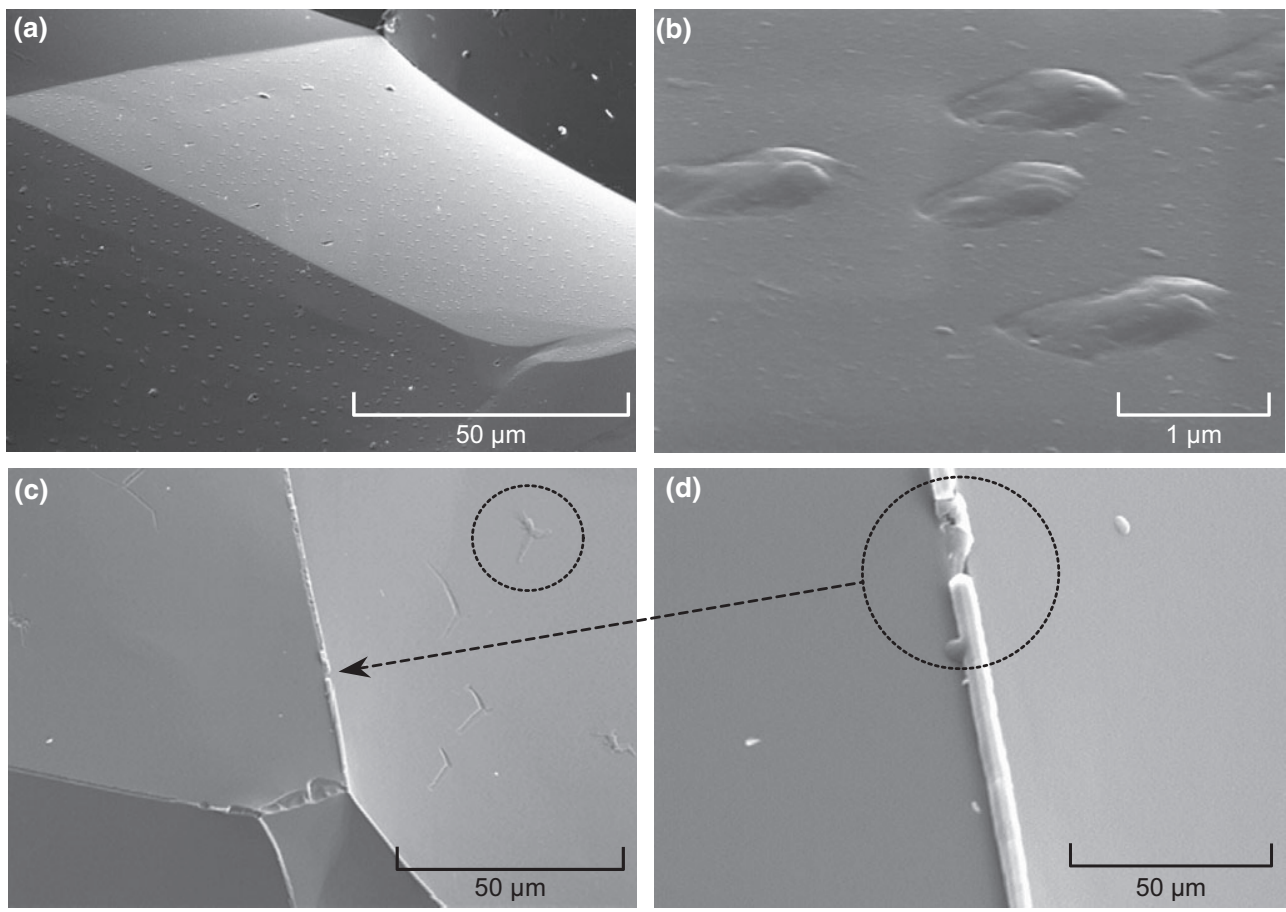

Fig. 16. Grain-boundary regions in spinel (TA): (a) and (b) high density of fine, alumina-rich particles; (c) coarse, angular particles; and (d) multigrain junction lined with alumina-rich phase.

the intergranular fracture. The residual stress at the interface between a particle and matrix of different properties can be estimated from the following ${ }^{23}$

$$
\begin{aligned}
\sigma & =-\left(\frac{\alpha_{\mathrm{p}}-\alpha_{\mathrm{m}}}{k}\right)\left(T_{\mathrm{f}}-T_{\mathrm{i}}\right) \text { with } \\
k & =\left(\frac{1+v_{\mathrm{m}}}{2 E_{\mathrm{m}}}\right)+\left(\frac{1-2 v_{\mathrm{p}}}{E_{\mathrm{p}}}\right)
\end{aligned}
$$

where $\alpha$ is the coefficient of thermal expansion, $v$ Poisson's ratio, $E$ Young's modulus, and $T$ the temperature with subscripts $p, m, i$, and $f$ corresponding to particle, matrix, initial, and final. The use of typical bulk properties for spinel and alumina results in stresses of $\sim 400 \mathrm{MPa}$, explaining the low strength, preferential crack path, and the cracked boundaries shown in Fig. 17. Spinel (TA) was also examined for texture by Electron Backscatter Diffraction. No texture was exhibited.

\section{(6) Weight Reduction}

With regard to slow crack growth, a window material's screening metric can be developed by using lifetime models 

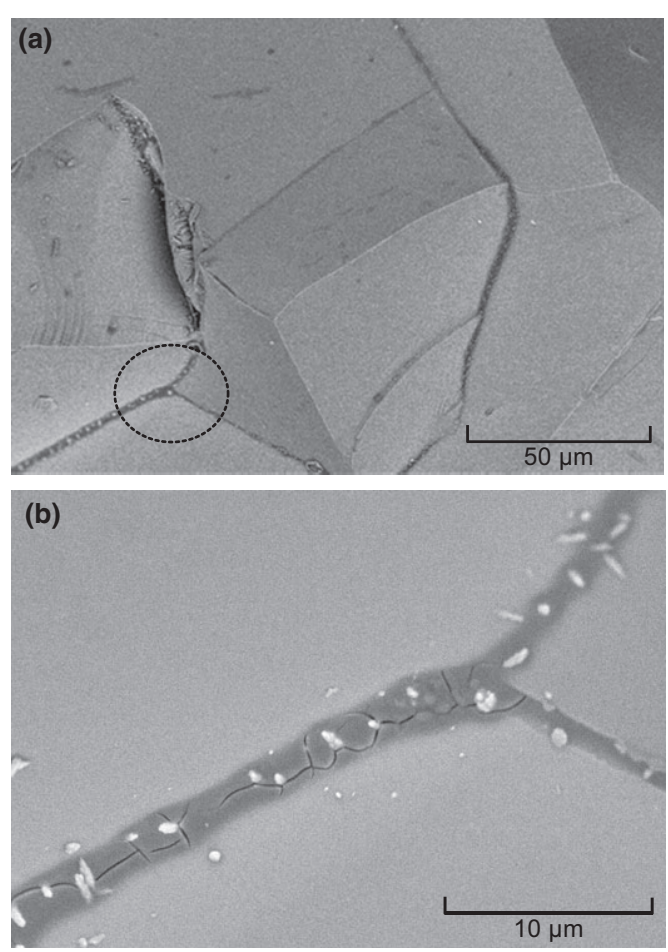

Fig. 17. Grain boundary in spinel (TA) exhibiting compositional variation (a) and micro-cracks (b).

for ceramics and glasses. The minimum life of a proof loaded component is ${ }^{24}$

$$
t_{\mathrm{f} \min }=B \sigma_{\text {proof }}^{n-2} \sigma_{\text {applied }}^{-n}
$$

where $B$ and $n$ are the slow crack growth constants and $\sigma_{\text {proof }}$ and $\sigma_{\text {applied }}$ are the proof and applied stresses. The mass and stress for a flat pressurized circular window are as follows

$$
m=\frac{\rho \pi D^{2} t}{4}
$$

and

$$
\sigma_{\max }=\frac{3 P D^{2}}{32 t^{2}}(3+v)
$$

where $\rho$ is the density, $v$ Poisson's ratio, $D$ window diameter, $t$ thickness, and $P$ applied pressure. The proof stress in terms of a screened flaw size is given as

$$
\sigma_{\text {proof }}=\left(\frac{K_{\mathrm{Ic}}}{Y \sqrt{a_{\max }}}\right)
$$

where $K_{\mathrm{Ic}}$ is the fracture toughness, $Y$ is the stress intensity factor coefficient, and $a_{\max }$ is the maximum flaw size after proof. Writing the window thickness in terms of the mass and substituting equations (4) through (6) into (3) and solving for the mass gives a function for the required window mass in terms of a minimum lifetime, pressure, screened flaws size, and crack growth parameters:

$$
m=\left(\frac{t_{\mathrm{f} \text { min }}}{B}\right)^{\frac{1}{2 n}}\left(\frac{K_{I c}}{Y \sqrt{a_{\max }}}\right)^{\frac{2-n}{2 n}}\left(\frac{3 \pi^{2} P \rho^{2} D^{6}}{512}(3+v)\right)^{\frac{1}{2}}
$$

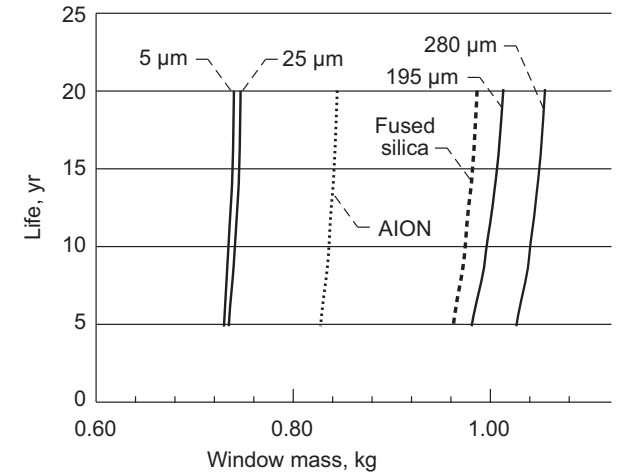

Fig. 18. Window lifetime as a function of mass for spinel of various grain sizes, ALON, and fused silica (50 $\mu \mathrm{m}$ starting flaw, one atmosphere).
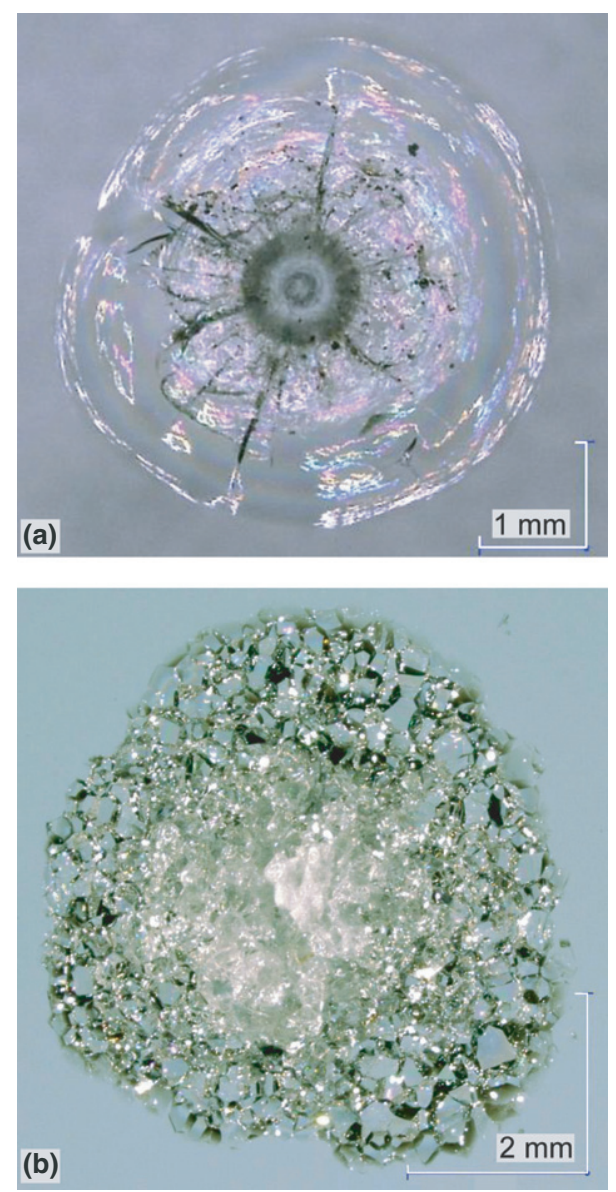

Fig. 19. Hyper-velocity impacts on (a) fused silica and (b) spinel (TA). Spinel exhibits localized cracking, whereas fused silica exhibits large, distinct cracks and spall.

or

$$
m=\left(\frac{A(n-2) t_{\mathrm{f} \min }}{2}\right)^{\frac{1}{2 n}}(a)^{n-2} / 4 \mathrm{n}\left(\frac{3 \pi^{2} P \rho^{2} D^{6} Y}{512}(3+v)\right)^{\frac{1}{2}}
$$

in terms of the constant $A$ in equation (1) The functions imply that the crack growth constants ( $n$ and $B$ ) and fracture toughness, which should be maximized, can be traded against density, which should be minimized. Figure 18 shows life as a function of mass for the materials in Table I, and implies 
that finer grained spinels and $\mathrm{AlON}$ can be used to lighten window systems from a slow crack growth perspective. More important is an ability to sustain damage from micrometeoroids and orbital debris, which is not easily predicted from materials property data.

Figure 18 also indicates that grain refinement beyond $25 \mu \mathrm{m}$ makes little difference in required mass, and that required mass is a weak function of lifetime for any material. Table $\mathrm{V}$ gives mass relative to that of fused silica for a $0.25 \mathrm{~m}$ window subjected to one atmosphere. Although the coarse-grained spinels (TA and AL) exhibit less mass benefit than fused silica, they may perform better under high velocity impact due to grain-boundary cracking and crushing, as shown in Fig. 19. Detailed study is required to determine the impacted related benefits.

\section{Conclusions}

The slow crack growth parameters and fracture toughness of transparent magnesium aluminate spinel and AlON are better than those of fused silica. These transparent ceramics have potential in spacecraft window systems despite higher densities. For spinel, a mass-lifetime relation indicates that grain size refinement below $\sim 150 \mu \mathrm{m}$ is necessary for improved mass, but little benefit occurs for refinement below $\sim 25 \mu \mathrm{m}$. Substantially more study is required to qualify transparent armor materials for manned spaceflight systems. Besides the meeting the metrics listed in the introduction, fine-grained spinel is difficult to manufacture in the dimensions desired for spacecraft windows.

In coarse-gained spinel, life-time growth can occur along a few preferential (weak) paths (large crystal planes and grain boundaries) due to intergranular fracture that is the result of porosity and residual stresses induced by alumina-rich regions and alumina platelets. However, as the grain size is refined, a shift from intergranular to transgranular fracture occurs and the mechanical properties improve. One spinel exhibited a strength gradient through the billet thickness due to variation in grain size. The resultant heterogeneity complicates Weibull scaling.

The use of single indentations to measure slow crack growth parameters and fracture toughness is less accurate for spinel due to poor crack formation. The use of multiple flaws reduces average strength and the coefficient of variation. A well-ground surface provides a multiplicity of surface cracks, thereby decreasing variability in slow crack growth measurements. This is opposite the behavior of glasses.

\section{Acknowledgments}

Thanks to Terry McCue for SEM fractography, Anita Garg for texture mapping, and Jeff Swab for supplying the AlON.

\section{References}

${ }^{1}$ J. M. Sands, P. J. Patel, P. G. Dehmer, A. J. Hsieh, and M. C. Boyce, "Protecting the Future Force: Transparent Armor Materials," AMPTIAC Quarterly, 8 [4] 28-36 (2004).

${ }^{2}$ S. Schwantes and W. Elbur, "Slow Crack Growth in Spinel in Water," NASA Technical Memorandum 85644 (1983).
${ }^{3}$ J. A. Salem and M. G. Jenkins, "Standardization Efforts for Mechanical Testing and Design of Advanced Ceramic Materials and Components"; in Proceedings of the 5th Conference on Aerospace Materials, Processes, and Environmental Technology (AMPET), Huntsville, AL, 2002.

${ }^{4}$ ASTM, "Standard Test Methods for Dynamic Young's Modulus, Shear Modulus, and Poisson's Ratio for Advanced Ceramics by Impulse Excitation of Vibration," Test Method C1259, Annual Book of ASTM Standards, Vol. 15.01. ASTM, West Conshohocken, PA, 2008.

${ }^{5}$ J. A. Salem and A. Singh, "Polynomial Expressions for Estimating Elastic Constants From the Resonance of Circular Plates," Mater. Sci. Eng., A, 422 292-7 (2006).

${ }^{6}$ ASTM, "Standard Test Methods for Determining Average Grain Size," Test Method E112, Annual Book of ASTM Standards, Vol. 03.01. ASTM, West Conshohocken, PA, 1996.

${ }^{7}$ ASTM, "Standard Test Methods for Fracture Toughness of Advanced Ceramics," Test Method C1421, Annual Book of ASTM Standards, Vol. 15.01. ASTM, West Conshohocken, PA, 2007.

${ }^{8}$ J. A. Salem, G. D. Quinn, and M. G. Jenkins, "Measuring the Real Fracture Toughness of Ceramics: ASTM C1421"; pp 531-53 in Fracture Mechanics of Ceramics: Active Materials, Nanoscale Materials, Composites, Glass, and Fundamentals. Edited by R. C. Bradt, D. Munz, M. Sakai and K. White. Springer, New York, NY, 2005.

${ }^{9}$ J. A. Salem and L. J. Ghosn, "Back-Face Strain for Monitoring Stable Crack Extension in Precracked Flexure Specimens," J. Am. Ceramic Soc., 93 [9] 2804-13 (2010)

${ }^{10}$ ASTM, "Standard Test Method for Flexural Strength of Advanced Ceramics at Ambient Temperature," Test Method C1161, Annual Book of ASTM Standards, Vol. 15.01. ASTM, West Conshohocken, PA, 2008.

${ }^{11}$ ASTM, "Standard Test Method for Determination of Slow Crack Growth Parameters of Advanced Ceramics by Constant Stress-Rate Flexural Testing at Ambient Temperature," Test Method C1368, Annual Book of ASTM Standards, Vol. 15.01. ASTM, West Conshohocken, PA, 2006.

${ }^{12}$ J. A. Salem and L. M. Powers, "Guidelines for the Testing of Plates", pp. 357-64 in Proceedings of the 27th International Cocoa Beach Conference on Advanced Ceramics and Composites: B, Ceramic Engineering and Science Proceedings, Vol. 24 [4] Edited by W. M. Kriven and H. T. Lin, The American Ceramic Society, Westerville, OH (January), 2003.

${ }^{13}$ ASTM, "Standard Test Method for Determination of Monotonic Biaxial Flexural Strength Advanced Ceramics," Test Method C1499, Annual Book of ASTM Standards, Vol. 15.01. ASTM, West Conshohocken, PA, 2008.

${ }^{14}$ J. A. Salem and M. G. Jenkins, "The Effect of Stress Rate on Slow Crack Growth Parameters," pp. 213-27 in Fracture Resistance Testing of Monolithic and Composite Brittle Materials, ASTM STP 1409, Edited by J. Salem, G. Quinn and M. Jenkins. American Society for Testing and Materials, West Conshohocken, PA, 2002.

${ }^{15}$ J. A. Salem and R. Tandon, "Test Method Variability in Slow Crack Growth Properties of Sealing Glasses," Int. J. Fatigue, 32, 557-64 (2010).

${ }^{16}$ R. L. Stewart and R. C. Bradt, "Fracture of Polycrystalline $\mathrm{Mg} \mathrm{Al}_{2} \mathrm{O}_{4}$," J. Am. Ceram. Soc., 63 [11-12] 619-23 (1980)

${ }^{17}$ A. Ghosh, K. W. White, M. G. Jenkins, A. S. Kobayashi, and R. C. Bradt, "Fracture Resistance of a Transparent Magnesium Aluminate Spinel," J. Am. Ceram. Soc., 74 [7] 1624 (1991).

${ }^{18}$ J. J. Swab, S. Kilczewski, R. Pavlacka, G. Glide, and D. Harris, "Strength of Coarse-Grained Transparent Spinel," Poster S4-P034-2011 at the International Conference on Advanced Ceramics and Composites, Poster Session A, Daytona Beach, January 25, 2011.

${ }^{19}$ R. L. Stewart and R. C. Bradt, "Fracture of Single Crystal $\mathrm{Mg} \mathrm{Al} \mathrm{O}_{2} \mathrm{O}_{4}$," J. Mater. Sci., 15 67-72 (1980).

${ }^{20}$ R. W. Steinbrech, O. Tokariev, and J. Malzbender, "Mechanical Characterization of a Transparent Spinel Ceramic," Presentation S1-031-2011 at 35th International Conference and Exposition on Advanced Ceramics and Composites, Symposia 1: Mechanical Behavior and Performance of Ceramics and Composites, Daytona Beach, January 23-28, 2011.

${ }^{21}$ O. Tokariev, R. W. Steinbrech, L. Schnetter, and J. Malzbender, "Microand Macro-Mechanical Testing of Transparent $\mathrm{MgAl}_{2} \mathrm{O}_{4}$ Spinel," J. Mater. Sci., 47 4821-6 (2012).

${ }^{22}$ S. M. Wiederhorn, A. G. Evans, E. R. Fuller, and H. Johnson, "Application of Fracture Mechanics to Space-Shuttle Windows," J. Am. Ceram. Soc., 54 [7] 319-23 (1974).

${ }^{23}$ J. Selsing, "Internal Stresses in Ceramics," J. Am. Ceram. Soc., Discussion and Notes, August 419 (1961)

${ }^{24}$ J. E. Ritter, "Engineering Design and Fatigue Failure in Brittle Materials," pp. 667-86 in Fracture Mechanics of Ceramics: Crack Growth and Microstructure, Vol. 4. Edited by R. Bradt, D. Hasselman, and F. Lang, Plenum, New York, NY, 1978. 